\title{
Potential of spatial use patterns for developing localized conditioning systems to reduce energy consumption
}

\author{
Nick Van Loy ${ }^{1, *}$, Griet Verbeeck ${ }^{1}$, and Elke Knapen ${ }^{1}$ \\ ${ }^{1}$ Sustaiability group, ARCK, Faculty of Architecture and Arts, 3500 Hasselt, Belgium
}

\begin{abstract}
In this paper, the spatial use of three underused semi-detached dwellings in Belgium is discussed. The exact user patterns of residents within rooms have been monitored during one week. In the analysis, a distinction has been made between spaces where people move through and have a higher metabolic rate and places where residents stay or sit for a longer time. The analysis shows that residents use some of the rooms only partially and others only for circulation. Furthermore, residents stay only at particular places in the room for a longer period of time. These zones or places are linked to the common activities. Nowadays, most dwellings are heated by a single-zone heating system that heats multiple rooms completely at the same time. However, the spatial use of residents not only shows that particular places in a room are used, but also that they are used at different times. This research illustrates the potential of spatial use patterns for the development of heating systems that are better adapted to the effective spatial use, the activity patterns and corresponding required temperature in residential buildings. This could result in a lower overall ambient temperature and an improved energy efficiency of the building.
\end{abstract}

\section{Introduction}

In order to reduce the energy consumption, dwellings are nowadays usually completely insulated causing a high material consumption and therefore, an increased material-related environmental impact. Furthermore, these dwellings are usually acclimatised by a central heating system that heats several rooms completely at the same time[1], while residents do not use them completely nor simultaneously, especially in the case of large underused dwellings. In Flanders, heating represents $50 \%-75 \%$ of the total household energy consumption [2]. Although the mismatch between spatial use and energy consumption by heating systems is known, there are only few insights into the effective spatial use of dwellings. The hypothesis is that the energy consumption of dwellings could be decreased when the installations for heating are better adapted to the effective spatial use, e.g. by (1) turning down the heating when a room is not used, (2) permanently decrease the temperature set point and using localized heating to ensure residents' comfort [3]. After all, the implementation of both strategies should not affect resident's thermal comfort. In recent years, several systems, such as $\mathrm{Tado}^{\circ}$, Eurotronic, Evohome from Honeywell have been developed to control individual rooms with programmable thermostatic valves, whether or not combined with the internet of things and/or with open window detection. These systems are able to lower the temperature when the room is not occupied.

By permanently decreasing the temperature set point, residents are not always satisfied with the thermal environment. Therefore, localized conditioning systems, which aim to create a comfortable microclimate around the user, could be introduced in dwellings. E.g., the use of heated chairs can allow to lower the overall room temperature while maintaining a comfortable thermal comfort for the user [4-7]. Research has shown that by implementing localized heating, up to $60 \%$ of the total energy consumption (heating, cooling and ventilation) can be saved [8]. However, most of this research applies to office buildings and cannot be extrapolated to residential buildings.

In contrast to office buildings, more diverse activities take place in a residential context, each with their own level of activity and required comfort temperature. For example: in general, circulation or cooking activities require lower temperatures than activities such as reading or watching television. In fact, the temperature can be lowered in certain rooms or even in certain zones within a room.

In order to develop a more adapted heating system for dwellings, insights must be gained into the effective spatial use of dwellings. Especially in underused dwellings, i.e. dwellings that are occupied by less residents than they were built for. Additionally,

\footnotetext{
* Corresponding author: Nick.vanloy@uhasselt.be
} 
implementing localized heating could be an alternative to a current cost and material intense renovation. This paper discusses the spatial use in three Flemish semidetached underused dwellings (section 2) and shows the potential of the spatial use patterns for developing more adapted heating systems (section 3 ).

\section{Spatial use patterns of semi-detached underused dwellings}

\subsection{Methodology}

To gain insights into the effective spatial use, three semidetached underused dwellings in Hasselt, Belgium, are monitored for one week between March and April 2018. In this paper, results are shown for one dwelling, but the conclusions are based on all three dwellings.

The dwellings occupied by respectively 2, 1 and 1 resident(s), were built in 1951, 1975 and 1952 and have roof insulation and double-glazing but no wall insulation. The dwellings are all heated by a central heating system controlled by one manual or programmable thermostat. This common way of heating [9], ensures that several rooms are fully heated when the heating is switched on. Only in one case, the resident changed the position of the radiator valves when entering or leaving a room although, this was limited to the kitchen and the workspace. The valves of the domestic heating elements discussed in this paper, were not changed during the monitoring period and were opened in the kitchen, dining room, living room and bathroom (fig 1).

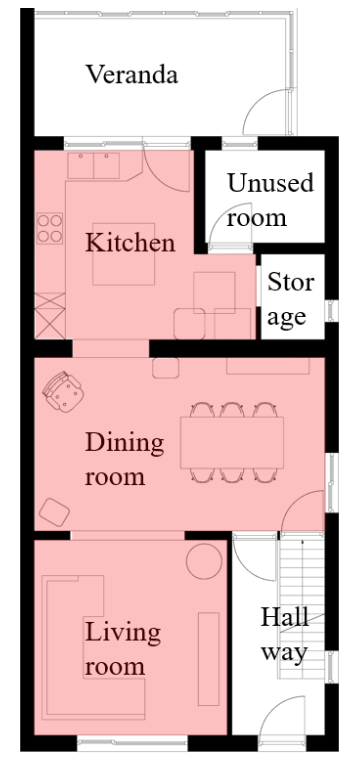

Ground floor

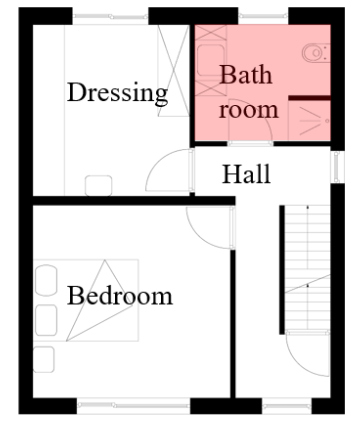

First floor
Fig.1. Floorplans of dwelling I with heated rooms in red.

During this monitoring campaign, the residents were asked to wear an indoor localisation system [10], when they were at home and awake. This system monitored their exact location in the dwelling, three times per second in this case. The residents were also asked to note their "actions" on the building and the systems, such as changing the temperature set point and opening or closing radiator valves, on pre-printed sticky notes that were placed on each heating element and window. Additionally, residents had to fill in a thermal comfort survey multiple times a day (each time they stayed for a longer time at a certain spot), with questions on their thermal comfort experience, clothing level and activity. In addition to the data collected by the residents, the temperature, relative humidity and light intensity were measured in each room.

The raw location data of the residents were afterwards processed by applying two filters. Firstly, an anatomic filter restricts the data to positions in the building. A moving average/median filter is then used to smooth out the data, resulting in smoother running lines.

To visualize and analyse the data, use intensity charts (fig 2) are created with Qgis [11]. In a second stage, standstills are defined when the resident remained for at least 60 seconds in a circle with a radius of $50 \mathrm{~cm}$. When a standstill is detected, the average location as well as the duration of the standstill are calculated and displayed on the map.

\subsection{Results}

\subsubsection{Use intensity of the dwelling}

The spatial use of both residents (fig. 2) reflects the use intensity of places in the dwelling. All observed positions are represented by dots on the map, both when the residents are walking and when they are standing still. A red colour indicates a high intensity of use. Figure 2 shows that only a few rooms are frequently used, some rooms are only partially used and some rooms are not used at all. The kitchen is used fully and very intensively. On the other hand, the veranda is used rarely and only partially. The dining room can be divided into zones with different usage intensities. The chair that is placed in the left upper corner, the connection zone between the kitchen and dining room, and one chair at the table are characterized by high intensity of use. The rest of the dining room is used less or not used. In the living room, some places are used more intensively, but they are all linked to the couch, while the rest of the living room shows a lower use intensity. In the hallway, an average use intensity is recorded with some high intensity spots near the front door. In the bathroom, a higher use intensity can be noticed in the toilet and the washbasin. The bedroom seems to be unused, but this is because residents turned off the tag when going to bed. The other rooms in the dwelling show less intensive use.

By comparing the effective spatial use (fig.2) with the way the house is heated (fig.1), it can be noticed that in the overall heating period the residents only heat the rooms that are used regularly, while in the unused rooms the heating elements were closed. However, still the entire rooms are acclimatized while only a part of them is used effectively. 


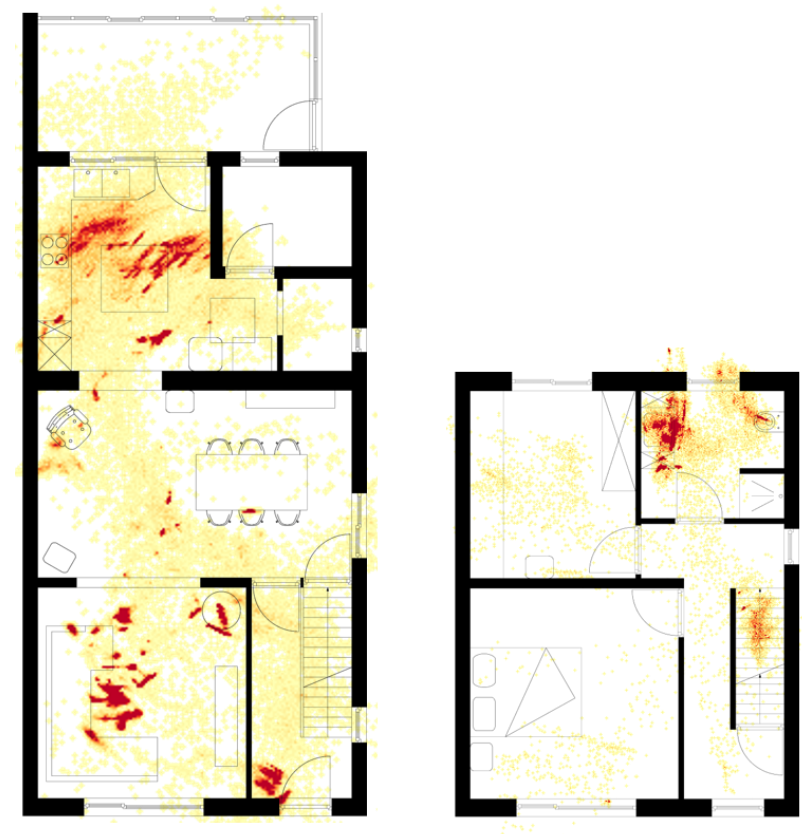

Fig.2. Use intensity of both residents in their dwelling during one week. The colour is more red when the intensity is higher.

Although, maps as fig. 2 show the use intensity within each room, they do not give insights into the zones or places where residents stay, nor differentiate between circulation and a standstill.

\subsubsection{Standstill places}

To discover places where residents stay, the localisation data are processed to discover "standstills". Standstills are defined as places where residents stay at least for one minute inside a radius of $50 \mathrm{~cm}$, illustrated by bubbles on Figure 3. The radius of each bubble indicates the duration of a standstill.

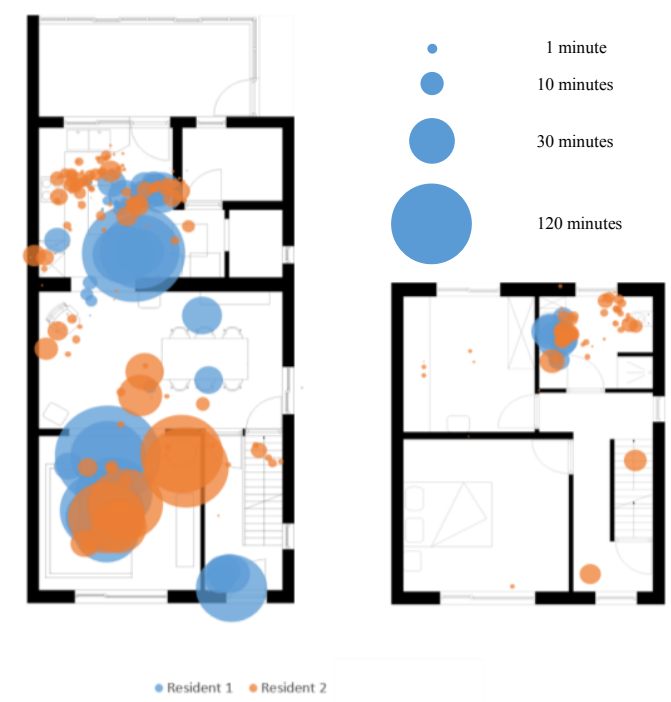

Fig. 3. Standstills of both residents during one week (heating period).

It turns out that residents only stay at particular spots. It also shows that there are both long and short stays in the kitchen. The shorter stays (1-10 minutes), mainly by resident 2 (red), mostly occur around the kitchen worktop and are linked to activities such as cooking and dishwashing, both characterized by more exercise and a higher metabolism. Longer stays (5 - 170 minutes) can be found at the dining table in the kitchen, which is mainly used for eating. Linking the survey with the temperature measurements showed that residents feel particularly comfortable in the kitchen at temperatures between $19,6-21,5{ }^{\circ} \mathrm{C}$. One of the residents once felt slightly cool during dinner, while the temperature was $19,8{ }^{\circ} \mathrm{C}$. At that time, the resident wore only very light clothing, unlike the other moments.

The combination of the use intensity in figure 2 and the standstills in figure 3 shows that the dining room is mainly used for circulation (fewer and smaller bubbles). The residents stayed there a few minutes for an average period of 15-30 min, and the survey showed that this was due to working, social interaction, relaxation or sports. The standstill occur at the dining table and at the chair in the upper left corner. Residents felt comfortable even with a temperature below $20^{\circ} \mathrm{C}$. During exercise, one resident perceived the temperature of $20^{\circ} \mathrm{C}$ and $21^{\circ} \mathrm{C}$ as too warm.

Figure 3 shows many larger bubbles in the living room, which means that the residents usually stayed there for a longer period ( 60 minutes or more). Many of these bubbles are located around the couch and some are in the corner of a table (by charging the tag while watching TV). Activities connected to this room are watching television, working on the computer, relaxing and social interaction that represent a relatively low metabolic rate (around $1 \mathrm{Met}$ ). The residents usually felt comfortable at temperatures between $19,4{ }^{\circ} \mathrm{C}$ and $22^{\circ} \mathrm{C}$, although they sometimes used an extra blanket. Both residents noticed that they felt too cold by $21,5^{\circ} \mathrm{C}$, but in that case, they wore only light clothing. This shows that residents could have improved their comfort by increasing their clothing insulation as they did on other moments.

In the bathroom, multiple bubbles of varying durations are spread throughout the room, however, they have a different duration at the toilet and washing table. The survey showed that the residents usually felt too cold in the bathroom with temperatures between $16,5^{\circ} \mathrm{C}$ and $20^{\circ} \mathrm{C}$.

In the other rooms, there were only small or no bubbles, meaning that residents stayed here only for a short time $(<3$ minutes) or only walked through the room. Bubbles on and near the stairs can be explained by the fact that the residents were renovating the stairs. No bubbles are shown in the bedroom, because the residents switched off the device when they go to bed.

If you compare the standstills with the way the dwelling is heated, it can be noticed that the residents only use certain spots in the rooms while the rooms are fully acclimatized. 


\subsubsection{Periods}

Although figures 2 and 3 show that residents do not use the entire room and only stay at certain locations in the room, these figures do not show the spatial use over time. Therefore, the localisation data are shown as a function of the different periods of a day in figure 4 .

In the morning (6 AM - $9 \mathrm{AM})$, the residents mainly used the kitchen for relatively short periods ( $\left.3^{\prime}-10^{\prime}\right)$ and the bathroom for short to medium periods (3'-23'). The other rooms are used rarely or not in the morning except the dining room for sports. This activity takes longer ( $\pm 30 \mathrm{~min}$ ) and is related to a higher metabolism.

Before noon (9 AM - $12 \mathrm{AM})$, the residents used the kitchen a lot, while the dining room was only used once. One of the residents used the living room for one hour on two different days. The bathroom was used only for short periods (less than 10 minutes).

In the afternoon (12 AM - 5 PM), the residents mainly stayed at the kitchen table and in the living room and bathroom, both for short as longer periods. During the weekend, the residents stayed at the staircase for renovating it.

In the early evening (5 PM - 7 PM), mainly the kitchen was used. In the other rooms, only a few bubbles appear and a few near the toilet in the bathroom. The other rooms are only used for short periods. One longer stay (27') was noticed in the dining room while there was social interaction with visitors.

Later in the evening (after 7 PM), the kitchen and bathroom are only used for shorter periods. The stays in the dining room are limited to the chair in the upper corner. Long stays are noted in the living room on the seat and some in the corner of the living room (charging the tag).

These standstills spread over time show that not all rooms are used simultaneously, while all these rooms are heated simultaneously by the central thermostat that controls the single zone. All the rooms are heated while some are not used or are only used for passing by.

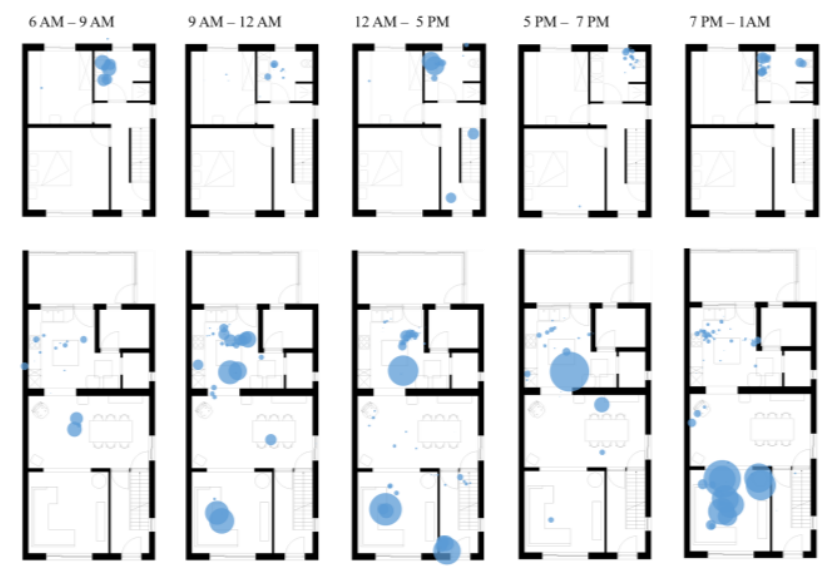

Fig. 4 Standstills of both residents during different time periods of the complete week.

\subsection{Conclusion for spatial use patterns}

The analysis of all three cases leads to similar conclusions. The analysis of the spatial use shows that not all rooms are used completely and that there are areas that are not used by the residents. The analysis of standstills shows that residents only stay for longer than 1 minute in certain zones within a room, such as around the kitchen worktop, at the kitchen/dining table and the desk, on the couch, and in the bathroom. The analysis of the spatial use as a function of time showed that not all rooms and places are used simultaneously.

By comparing the actual spatial use with the current installed heating system, three inefficiencies are found. Firstly, rooms are completely heated while they are only partially used, e.g. the dining and living room. Secondly, only particular spots are used in the rooms or some rooms are only used as circulation while the whole room is heated, e.g. the living room. Both inefficiencies are linked to the fact that the rooms are heated with a convectional heating system. By analysing the variation of spatial use over time, a third inefficiency is found, because not all rooms are used in the same period while a single zone control system heats all these rooms at the same time.

In section 3, the lessons from the effective spatial use are used to propose different techniques that adapt better to the actual use of space. By using better-adapted heating systems, energy could only be used in places where residents are present and a higher energy efficiency could be reached.

\section{More adaptive heating systems}

Three different scales of heating can be distinguished (fig 5) based on the identification of the abovementioned inefficiencies. The first scale describes the most common situation in dwellings in Belgium [9] where all commonly used rooms are heated and the heating system is only controlled by one thermostat, usually placed in the living room. At a second scale, multi room heating is introduced, whereby multiple zones or even each heating element can be controlled individually and can be more adapted to the occupancy of the room. The energy savings will be less when rooms cannot be separated from each other e.g. in case of an open kitchen, open living and dining room or when the doors between the rooms are not closed [1]. At the third scale, localized heating systems in specific zones within a room are considered. Only zones where residents stay, will be acclimatized while the ambient temperature in the rest of the room is lowered. Energy can be saved because it is more efficient to heat an individual human, instead of the complete space [6]. To implement localized heating, other methods of heat transfers are needed. Nowadays, most heating systems are based on convection that heats the air in the space, while localized heating is mostly focussing on conduction or radiation to achieve thermal comfort. In following paragraphs, multizone and localized heating systems are discussed. 


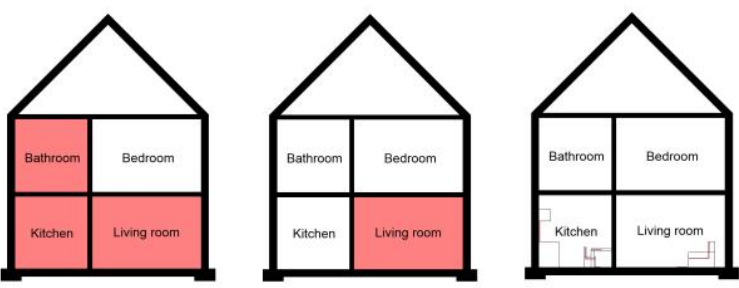

Fig. 5. Three different scales of heating: simultaneous heating of all used rooms (left), multi-zone heating (middle), localized heating (right).

\subsection{Multi-zone heating}

Today, most heating systems are equipped with a single zone thermostat and thermostatic valves on the heating elements to control the temperature in each room. The valves can be used to lower the heating set point in that room, but most residents do not change it when entering or leaving the room. By implementing multi-zone heating, energy savings can be achieved because several zones or even each heating element can be digitally controlled and the temperature in the room can be lowered when not in use. Studies $[1,12]$ have shown that multi-zone heating has an energy saving potential of $12 \%-31 \%$ (for semi-detached housing). Multi-zone heating can be realized in different ways. Firstly, the complete systems can be adapted whereby different circuits are implemented which are controlled by different thermostats. However, changing the heating system has its cost and is not always possible in existing buildings. Therefore, as second option, low cost programmable thermostatic valves controlled by the user can be installed. They can be combined with a smart thermostat that controls the boiler and can be connected to the internet, but this is not necessary. This way, a multi-room system works as a cost effective upgrade of the existing system, especially in older buildings where other energy saving possibilities are limited. However, when rooms cannot be separated from each other or when the doors are not closed, the energy savings drop dramatically [1].

\subsection{Localized heating}

In recent years, localized heating received a lot of attention in office buildings to increase the thermal comfort of employees. Historically, in houses, localized heating through e.g. a stove was used as a radiative heat source while the background temperature was relative low [13]. Over the years, central heating systems with radiators, convectors or floor heating became the new standard for heating that fully heats multiple rooms. Reintroducing localized heating in fully acclimatized buildings is a newer phenomenon that is less studied. These systems aim to heat only specific spots, where the resident is located at that moment, and, at the same time, the overall ambient temperature can be lowered. Recent studies have shown that with localized heating it is possible to lower the heating set point without lowering or even increasing the thermal comfort of the users $[6,8$,
14]. Lowering the temperature set point from 21,5 to $18^{\circ} \mathrm{C}$ can save $35 \%$ to $40 \%$ of the HVAC energy consumption depending on the climate and the type of house $[14,15]$. In dwellings respectively $23 \%$ to $34 \%$ can be saved by lowering the temperature from $21^{\circ} \mathrm{C}$ to $19^{\circ} \mathrm{C}$ during the heating period in Copenhagen and Madrid [16]. However, when considering energy savings by reducing the heating set point, the additional energy consumption of the applied localized heating system that depends on the used system, the duration of use etc., has to be taken into account.

Analysis of the standstills shows the potential to implement localized heating systems at several places (fig.6) that require different temperatures. These are the kitchen/dining table, desk and the couch in the (living) room for longer stays and in the bathroom and the kitchen worktop for shorter stays. Objects that are now playing a passive role in acclimatisation, such as the couch and the table can be upgraded to active elements that contribute to thermal comfort. In the next subsections, elements and spots that show potential, are discussed and possible localized heating systems for dwellings are proposed based on literature. These systems need to have a short response time to avoid thermal discomfort.
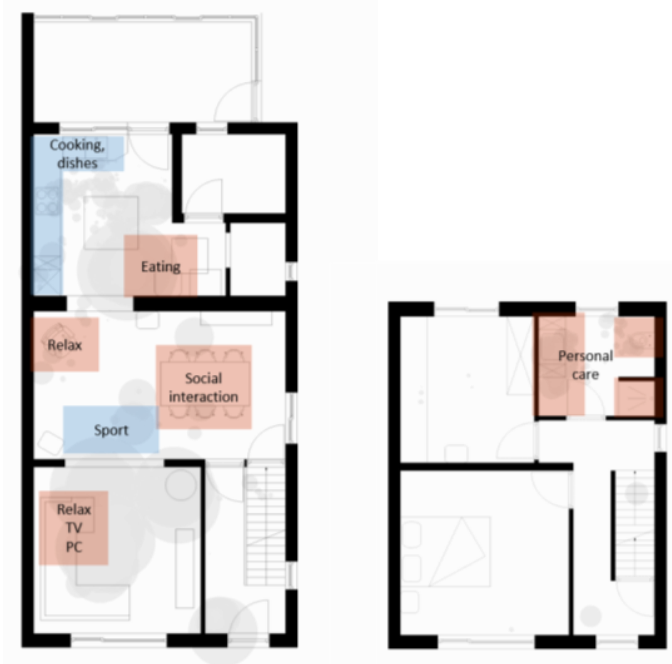

Fig. 6. Potential places to implement localized conditioning systems.

\subsubsection{Couch}

In the living room, the couch can be determined as the most common place used by residents. Heated couches are barely studied, whereas, the effect of a heated couch could be comparable with that from an office chair which is well studied in climate chambers for comfort improvements and energy reductions. Zhang et al. [4] showed that $90 \%$ of the users are satisfied at a room temperature of $15,6^{\circ} \mathrm{C}$ while using a heated seat. Pasut et al. [5] found that $80 \%$ of the users is satisfied with room temperatures of $16^{\circ} \mathrm{C}$ while using the heated chair. Watanabe et al. [7], who studied the performance of a convection-heated chair, showed that a heated chair in a 
room of $20^{\circ} \mathrm{C}$ can give the feeling of $22.1^{\circ} \mathrm{C}$. Luo et al. [6] studied different combinations of a heated chair, heated insoles and wrist heating. When sitting on a heated chair, $91 \%$ of the users are satisfied with an ambient temperature of $18^{\circ} \mathrm{C}$. These studies show that a heated chair has a large potential to satisfy people when the indoor temperature is lowered. To ensure thermal comfort at residents' feet, heated socks, heated insoles, heated shoes or a heated mat can be used. In the study of Luo et al. [6], heated insoles are used to increase the comfort of the user's feet. The heated insoles on their own could satisfy $80 \%$ of the participants with an ambient room temperature $18^{\circ} \mathrm{C}$. These techniques can be combined with a blanket that is already frequently used for comfort improvements and/or for cosiness.

\subsubsection{Kitchen/dining table and desk}

The behaviour of residents at the kitchen table, dining table and desk is similar to each other. Inspiration of office buildings can be used for developing localized heating for these places. Not all body parts are equally sensitive to cold. By heating the most sensitive body parts, an overall thermal comfort could be reached. Luo et al. found that a combination of seat heating, wrist heating and feet heating gives the best results [6]. This combination could satisfy $97,5 \%$ of the people at an ambient temperature of $18^{\circ} \mathrm{C}$.

\subsubsection{Bathroom}

The bathroom is a place that is used for short and long periods. The furniture in the bathroom does not have direct contact with the residents. Therefore, radiant heating panels could be used when the room is only used for a short period because of its quick response time. This makes it possible to move through the room without being uncomfortable. In a bathroom, radiant heating panels can be combined with the mirror or can be placed at the ceiling. Watanabe et al. [7] studied a floor radiant panel and showed that with an ambient temperature of $20^{\circ} \mathrm{C}$, residents experience a temperature of $22,1^{\circ} \mathrm{C}$ and $22,8^{\circ} \mathrm{C}$. When the room is used for a longer period, the set point of the heating can be increased because the volume of these rooms is mostly relatively small. However, this depends on the duration of the periods, the buildings characteristics and the outside temperature.

\subsubsection{Kitchen worktop}

Shorter standstills in the kitchen mainly occur at the kitchen worktop. Because the residents move along the worktop, their metabolic rate will be higher and they may feel comfortable at lower temperatures. However, when they need a higher comfort, it is more difficult to implement local heating because they are not standing on one specific location. Therefore, radiant heating panels can be applied to the ceiling of the work area

\subsubsection{Conclusion}

Several local conditioning systems for heating studied in literature are discussed in relation to the standstill locations identified in section 2 . These systems can have great potential for energy savings, but can also have a positive impact on the thermal comfort of the users. However, most systems are designed for office buildings and further research is needed to adapt them to the specific needs in dwellings. Energy can be saved by lowering the ambient temperature and applying local heating systems if the energy consumption of the local heating system is lower than the energy saved by lowering the indoor air temperature. Therefore, systems such as convective heaters used by some residents cannot be considered energy efficient.

\section{Conclusion}

The analysis of the spatial use of three semi-detached dwellings in Flanders has shown that residents do not use the spaces completely nor simultaneously. Standstill locations, extracted from the localisation data of the residents, indicate that residents only stay at specific spots within rooms for more than one minute. Short-stay as well as long-stay locations are identified in function of time. Comparing effective spatial use with the way in which residents heat their dwelling, three inefficiencies can be identified. Different heating systems that can be adapted to the actual space use are proposed to increase energy efficiency. Firstly, all rooms are heated simultaneously while the rooms are used at different times. Multi-zone systems can control the heating elements individually, whereby the rooms are only heated when the room is occupied. Secondly, the rooms are completely acclimatized while residents do not use the complete room and only stay in certain places of the room. By using local condition systems, it is possible to lower the total temperature setting point, which can lead to energy savings. This approach can be applied in older buildings as an alternative for the current cost and material intensive renovation.

\section{Future work}

This paper shows the potential of spatial use patterns for applying localized heating in Flemish dwellings. Based on literature, conceivable systems are proposed. However, their effect on residents' thermal comfort as well as on the energy consumption is not tested in a real residential environment yet. In future work, a test case will be set up to evaluate the effect of these systems on residents' thermal comfort.

\section{References}

1. J. Cockroft, A. Cowie, A. Samuel, and P. Strachan, Energy Build. 136, 1-11 (2017)

2. J. Vandenabeele, viWTA.samenleving \& technologie (2005) 
3. T. von Bomhard, D. Wörner, and M. Röschlin, Computer Science - Research and Development 31, 127-134 (2016)

4. Y.F. Zhang, D.P. Wyon, L. Fang, and A.K. Melikov, Ergonomics 50, 586-600 (2007)

5. W. Pasut, H. Zhang, E. Arens, S. Kaam, and Y. Zhai, HVAC\&R Res 19, 574-583 (2013)

6. M. Luo, E. Arens, H. Zhang, A. Ghahramani, and Z. Wang, Build. Environ. 143, 206-216 (2018)

7. S. Watanabe, A.K. Melikov, and G.L. Knudsen, Build. Environ. 45, 549-558 (2010)

8. M. Veselý and W. Zeiler, Renew Sust Energ Rev 34, 401-408 (2014)

9. L. Peeters, J. Van der Veken, H. Hens, L. Helsen, and W. D'haeseleer, Energy Build. 40, 1446-1455 (2008)

10. N. Van Loy, G. Verbeeck, and E. Knapen, Measuring Behaviour 2018 342-348, (2018)

11. QGISDevelopmentTeam. QGIS Geographic Information System. (2018).

12. A. Beizaee, D. Allinson, K.J. Lomas, E. Foda, and D.L. Loveday, Energy Build. 92, 29-44 (2015)

13. H. Zhang, E. Arens, and Y. Zhai, Build. Environ. 91, 15-41 (2015)

14. Udayraj, Z. Li, Y. Ke, F. Wang, and B. Yang, Build. Environ. 143, 1-14 (2018)

15. T. Hoyt, E. Arens, and H. Zhang, Build. Environ. 88, 89-96 (2015)

16. A. Ghahramani, K. Zhang, K. Dutta, Z. Yang, and B. Becerik-Gerber, Appl Energ 165, 930942 (2016) 